\title{
Erratum: Epicatechin blocks pro-nerve growth factor (proNGF)-mediated retinal neurodegeneration via inhibition of p75 neurotrophin receptor expression in a rat model of diabetes
}

M. M. H. Al-Gayyar • S. Matragoon • B. A. Pillai •

T. K. Ali • M. A. Abdelsaid • A. B. El-Remessy

Published online: 19 January 2011

(C) Springer-Verlag 2011

\section{Erratum to: Diabetologia}

DOI 10.1007/s00125-010-1994-3

Unfortunately, the title of the original article was incorrect. It should have read 'Epicatechin blocks pro-nerve growth factor (proNGF)-mediated retinal neurodegeneration via inhibition of $\mathrm{p} 75$ neurotrophin receptor expression in a rat model of diabetes'.

The online version of the original article can be found at http://dx.doi. org/10.1007/s00125-010-1994-3

M. M. H. Al-Gayyar · S. Matragoon • B. A. Pillai - T. K. Ali •

M. A. Abdelsaid - A. B. El-Remessy $(\square)$

Clinical and Experimental Therapeutics, College of Pharmacy,

University of Georgia,

Augusta, GA 30912, USA

e-mail: aelremessy@mcg.edu

A. B. El-Remessy

Department of Pharmacology and Toxicology,

Medical College of Georgia,

Augusta, GA, USA

\section{A. B. El-Remessy}

Department of Ophthalmology, Medical College of Georgia,

Augusta, GA, USA

M. M. H. Al-Gayyar · S. Matragoon • B. A. Pillai - T. K. Ali • M. A. Abdelsaid · A. B. El-Remessy

Veterans Affairs Medical Center,

Augusta, GA, USA

Present Address:

M. M. H. Al-Gayyar

Department of Biochemistry, Faculty of Pharmacy,

University of Mansoura,

Mansoura, Egypt

Present Address:

T. K. Ali

Medical Center of Little Rock,

Little Rock, AR, USA 